\title{
Response of Plasma Aldosterone to Postural Change, Diuretica, Angiotensin II, Sodium Restriction or Loading and Prostaglandin
}

\author{
Teizo Iro, M.D.,* Hirosi Hidaka, M.D., Tatuo Kato, M.D., \\ and Yawara Yoshitoshi, M.D.**
}

\section{SUMmaRY}

This paper shows the result of plasma aldosterone which was measured by radioimmunoassay method using aldosterone-3-carboxymethoxamineBSA or aldosterone-hemisuccinate-BSA. Normal control value at recumbency or upright, primary aldosteronism, uremia, essential hypertension and miscellaneous diseases were examined.

By diuretica, plasma aldosterone of normal volunteer was increased but that of patients with edema was decreased temporarily. The response of plasma aldosterone in edematous patient to the constant infusion of Angiotensin II, was stronger than that of normal volunteer. But primary aldosteronism with adenoma showed the sequentially decreased plasma aldosterone by the constant infusion of Angiotension II. Some of the primary aldosteronism showed the normal response to the sodium loading and restriction. By the pressure dose Prostaglandin $A_{2}$ or $E_{1}$ infusion, the plasma aldosterone showed a tendency to increase.

\section{Additional Indexing Words:}

Radioimmunoassay Edema Primary aldosteronism

7 HE measurement of plasma aldosterone is widespreading rapidly. Up to now, it was measured by the double isotope method but this contained much problem about reliability or reproducibility.

Recently the development of radioimmunoassay method, however, conquered this problem. Renin-angiotensin-aldosterone system has a feed-back system. But in some disorders this system does not always act as normal. The measurement of aldosterone is necessary to elucidate this mechanism. In this paper, not only renin-angiotensin system but also other factors which influence to plasma aldosterone were studied.

* Clinical Research Department, Japan Self Defence Force Central Hospital.

** First Department of Internal Medicine, Faculty of Medicine, University of Tokyo.

Address reprint request to: Dr. Teizo Ito, Glinical Research Department, Self Defence Force Central Hospital, 1-2-24, Ikejiri, Setagayaku, Tokyo, Japan.

Received for publication September 14, 1973. 


\section{Materials And Methods}

Several normal volunteers, 16 hospitalized primary aldosteronism, 8 uremic patients, 7 essential hypertensive patients, 11 congestive heart failure, 3 Cushing's disease, 2 Bartter's syndrome, 2 liver cirrhosis with ascites and 1 congenital adrenal hyperplasia were studied.

a) Influence of postural change

Plasma aldosterone of normal volunteers and patients suffering from miscellaneous diseases was measured in the morning at recumbency. The former was measured again after upright and walking during 2 hours and compared with the value of recumbency. All of these volunteers were not put on diet control during this experiment.

b) Influence of furosemide

Furosemide $100 \mathrm{mg}$ was intramuscularly injected in normal volunteers and patients with edema. Before and after injection, at the interval of $15 \mathrm{~min}$, the blood was drawn 6 times from cubital vein and aldosterone was measured. During these procedures, blood pressure, hematocrit, urine volume and urine electrolytes were measured.

c) Influence of Angiotensin II

Angiotensin II $10 \mathrm{ng}$ per $\mathrm{Kg}$ per minute in $250 \mathrm{ml}$ saline solution was intravenously drop infused during 1 hour in normal volunteers, primary aldosteronism and edematous patients. Plasma aldosterone was measured before and after procedure at the interval of $15 \min 6$ times. At the same time, blood pressure, hematocrit and pulse rate were observed.

d) Sodium restriction and loading conditions:

Plasma aldosterone of primary aldosteronism was measured in the following

1) at the recumbency in early morning,

2) at the same condition after 3 days of sodium restricted diet (almost $3 \mathrm{Gm}$ of sodium chloride per day),

3 ) at the same condition after 3 days of sodium loaded diet (almost $20 \mathrm{Gm}$ of sodium chloride per day).

e) Influence of Prostaglandin

Prostaglandin $\mathrm{A}_{2} 50$ to $140 \mathrm{ng}$ per $\mathrm{Kg}$ per minute or Prostaglandin $\mathrm{E}_{1} 100 \mathrm{ng}$ per $\mathrm{Kg}$ per minute was constantly infused to a hypertensive patient and normal dogs.

\section{RESULTS}

a) Plasma aldosterone of normal volunteer and the patients suffering from miscellaneous diseases:

The result of Fig. 1 (left) shows plasma aldosterone of normal volunteer (recumbency or upright), primary aldosteronism, uremia (nephritis, malignant hypertension), essential hypertension, congestive heart failure, congenital adrenal hyperplasia and Bartter's syndrome. Normal range was distributed 0 to $28 \mathrm{ng} / 100 \mathrm{ml}$ and the mean was $9.24 \pm 6.28$ (S.D.) $\mathrm{ng} / 100 \mathrm{ml}$. In 8 of 16 cases of primary aldosteronism it was 50 to $244 \mathrm{ng} / 100 \mathrm{ml}$, and in other 8 

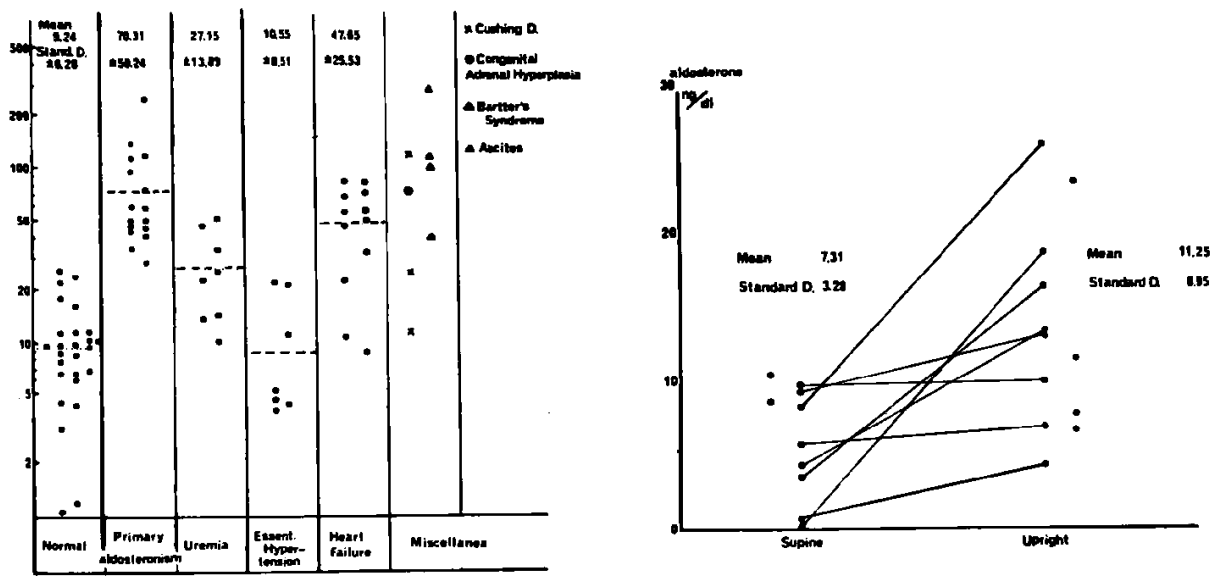

Fig. 1. Plasma aldosterone level in normal volunteer at recumbency or upright and various diseases (left). Postural change of plasma adosterone in normal volunteers (right).

cases it was 28 to $50 \mathrm{ng} / 100 \mathrm{ml}$. The mean was $70.31 \pm 50.24$ (S.D.) $\mathrm{ng} / 100 \mathrm{ml}$. The patients of renal disease with uremia showed the upper limit of normal range or slightly elevated value and its mean was $27.15 \pm 13.89$ (S.D.) ng/ $100 \mathrm{ml}$. Seven cases of essential hypertension were within normal range and its mean was $10.55 \pm 8.51$ (S.D.) $\mathrm{ng} / 100 \mathrm{ml}$.

One congenital adrenal hyperplasia was $66.1 \mathrm{ng} / 100 \mathrm{ml}, 2$ cases of Bartter's syndrome were 268 and $99 \mathrm{ng} / 100 \mathrm{ml}$ respectively. Two patients of liver cirrhosis with ascites were as high as 38 and $107 \mathrm{ng} / 100 \mathrm{ml}$. Three Cushing disease were $10.5,24.2$ and $112.5 \mathrm{ng} / 100 \mathrm{ml}$.

b) Influence of the postural change:

Fig. 1 (right) shows plasma aldosterone of normal volunteer at recumbency and after walking for 2 hours in the morning. The mean value of 10 cases at recumbency was $7.31 \pm 3.28$ (S.D.) $\mathrm{ng} / 100 \mathrm{ml}$. The mean value after walking of 8 out of above 10 cases was $11.25 \pm 8.96$ (S.D.) ng/100 ml. This was statistically significant.

c) Influence of diuretica:

Fig. 2 shows the plasma aldosterone before and after intramuscular injection of furosemide $100 \mathrm{mg}$ in one volunteer. Each sample was drawn at an interval of $30 \mathrm{~min}$. Hematocrit, urine electrolytes and volume were measured simultaneously. After the injection, urine volume and $\mathrm{Na}$ excretion were slightly increased. As $\mathrm{K}$ excretion was almost unchanged, $\mathrm{Na} / \mathrm{K}$ ratio was increased. Before procedure, plasma aldosterone was $5.8 \mathrm{ng} / 100 \mathrm{ml}$. After that it was $12.9,11.5,22.3,19.3$, and $6.9 \mathrm{ng} / 100 \mathrm{ml}$ respectively. This might mean that the dehydration and sodium diuresis increased the plasma aldosterone slightly. 

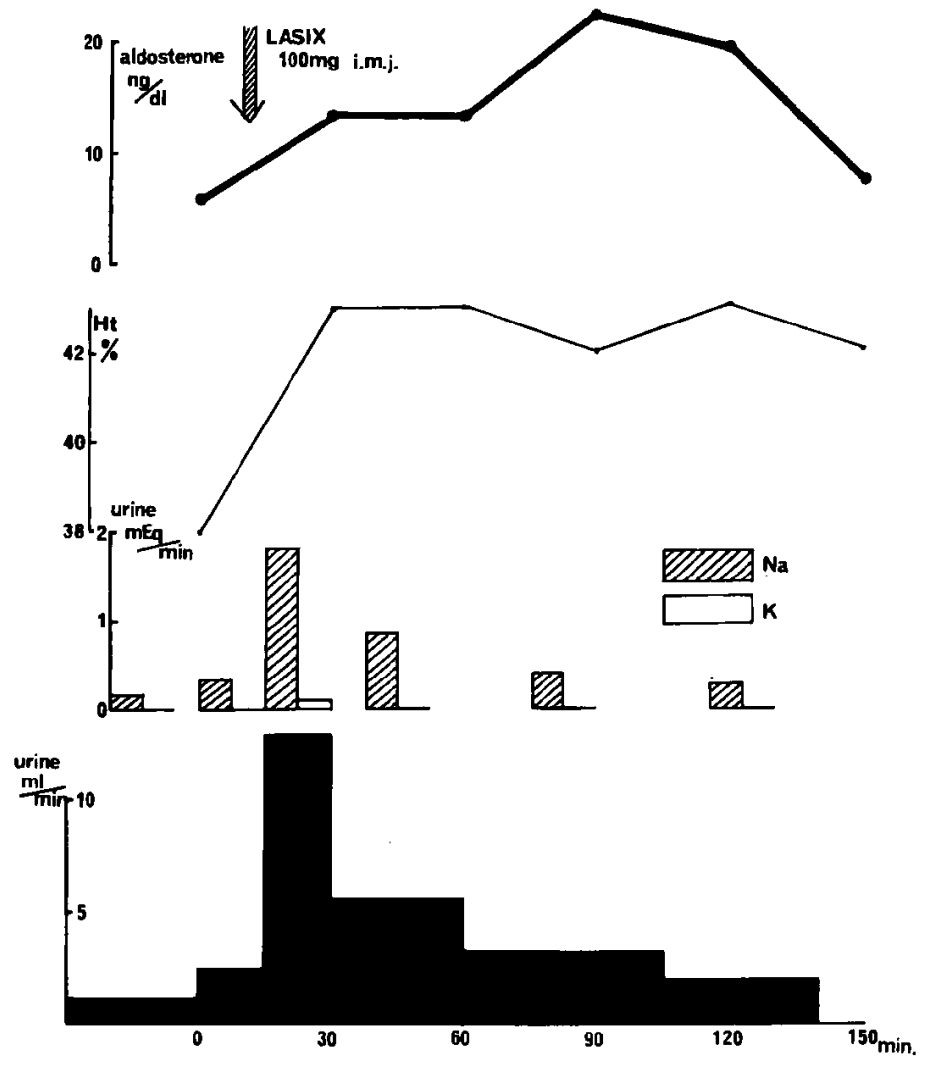

Fig. 2. The response of plasma aldosterone level to furosemide $100 \mathrm{mg}$ intramuscular injection in normal volunteer.

Same method was tried to the patients suffering from liver cirrhosis with ascites and congestive heart failure with edema (Fig. 3 left and right). Both patients showed markedly increased sodium excretion and increased $\mathrm{Na} / \mathrm{K}$ ratio and decreased urine osmotic pressure.

In patient with ascites, 2 samples drawn before procedure showed 101 and $103 \mathrm{ng} / 100 \mathrm{ml}$ and after diuresis the values in $30 \mathrm{~min}, 1,2,3,4,5$, and 6 hours were $71.1,67.9,73.0,68.1,69.5,69.5$, and $58.8 \mathrm{ng} / 100 \mathrm{ml}$ respectively. In patient of congestive heart failure, the values before procedure were 28.0 and $30.5 \mathrm{ng} / 100 \mathrm{ml}$ and after $1,2,3,4$, and 6 hours of procedure, the values of plasma aldosterone were $10.3,11.5,6.0,8.1$, and $9.5 \mathrm{ng} / 100 \mathrm{ml}$ respectively.

These results mean that the trend of plasma aldosterone in edematous patient exhibits a different behavior from normal volunteers.

Nine and 24 hours after furosemide procedure, the aldosterone of an edematous patient markedly increased, such as 73 and $125 \mathrm{ng} / 100 \mathrm{ml}$, although it was not pointed out in this figure. Such a phenomenon seems to show 

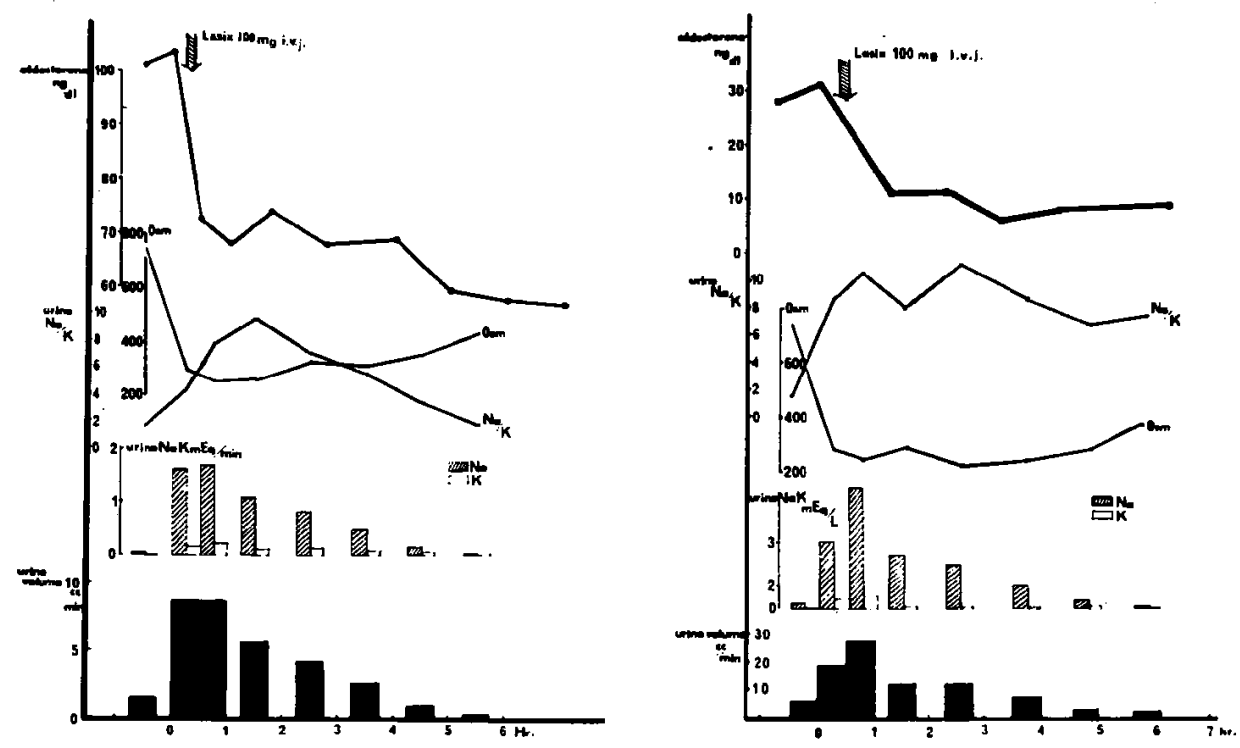

Fig. 3. The response of plasma aldosterone level to furosemide $100 \mathrm{mg}$ intravenous injection in liver cirrhosis (left). The response of plasma aldosterone level to furosemide of same dose in congestive heart failure (right).
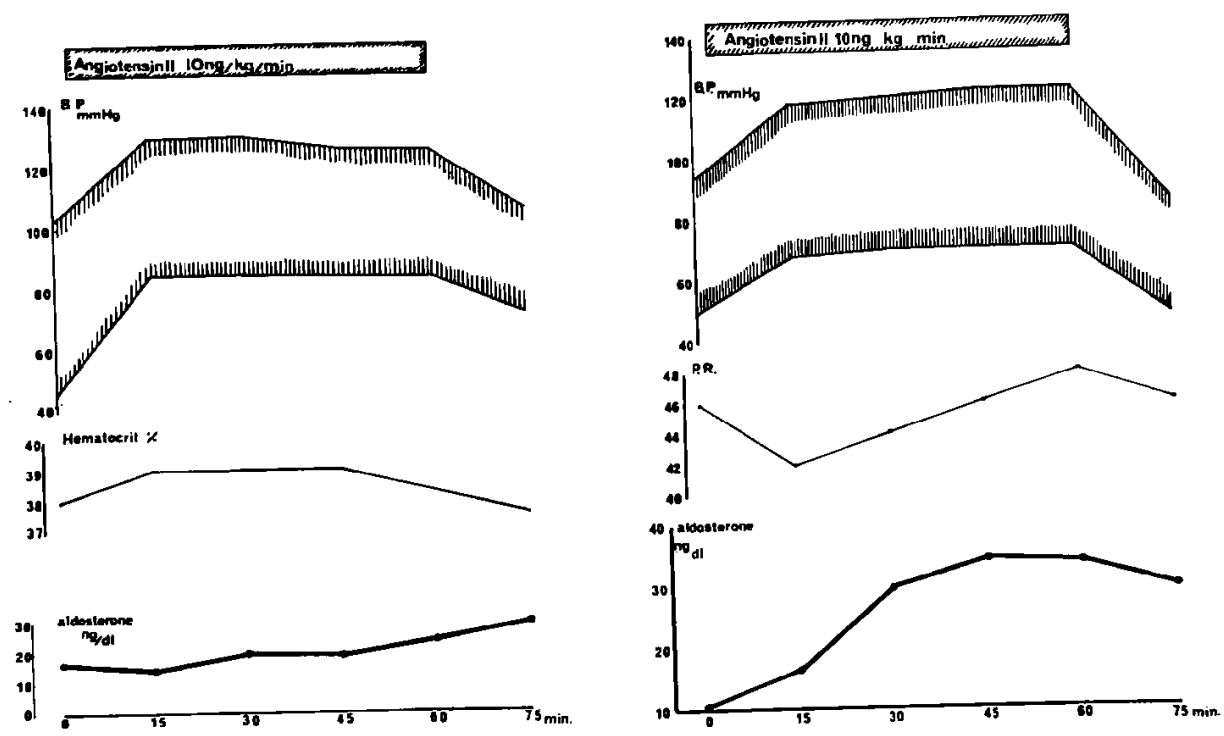

Fig. 4. The response of plasma aldosterone level to Angiotensin II $10 \mathrm{ng} / \mathrm{Kg} / \mathrm{min}$ infusion in 2 normal volunteers.

so-called " rebound," while the cause is not clear.

d) Influence of Angiotensin II constant infusion:

Fig. 4 (left and right) shows the change of blood pressure and plasma aldosterone during 1 hour constant infusion of Angiotensin II at the rate of 
$10 \mathrm{ng}$ per $\mathrm{Kg}$ per minute. Plasma aldosterone of one volunteer in Fig. 4 (left) showed $15.8 \mathrm{ng} / 100 \mathrm{ml}$ in pre-infusion and thereafter the values determined at $15 \mathrm{~min}$ interval after the beginning of constant infusion were 14.0, 19.4, 18.8, 23.4, and $29.1 \mathrm{ng} / 100 \mathrm{ml}$ respectively. Another volunteer (Fig. 4, right) showed $10.3 \mathrm{ng} / 100 \mathrm{ml}$ in pre-infusion and thereafter $16.4,29.6,34.4,33.9$, and $29.9 \mathrm{ng} / 100 \mathrm{ml}$ respectively.

The increase of systolic and diastolic blood pressure were $26 \mathrm{mmHg}$ and $44 \mathrm{mmHg}$ in the former and $28 \mathrm{mmHg}$ and $20 \mathrm{mmHg}$ in the latter respectively. The former showed the slightly increased hematocrit, and the latter showed the decreased pulse rate. The same procedure was tried to the primary aldosteronism, who was confirmed to have had the adenoma of $16 \mathrm{~mm}$ diameter by operation.

As shown in Fig. 5 (left), the plasma aldosterone of pre-infusion was as high as $56.8 \mathrm{ng} / 100 \mathrm{ml}$. At an interval of $15 \mathrm{~min}$ after the start of constant infusion, the values of plasma aldosterone were 54.5, 43.2, 38.5, 30.9, and $30.3 \mathrm{ng} / 100 \mathrm{ml}$. Systolic and diastolic blood pressure were increased $27 \mathrm{mmHg}$ and $15 \mathrm{mmHg}$ respectively. Fig 5 (right) shows the result in this patient obtained by the same procedure after 18 days of adrenalectomy. The plasma aldosterone before infusion was $2.0 \mathrm{ng} / 100 \mathrm{ml}$ and after infusion it was 5.8 , $5.0,10.7,24.1$, and $8.7 \mathrm{ng} / 100 \mathrm{ml}$ respectively. This shows the same reaction with normal persons.

Fig. 6 shows the result in another case of primary aldosteronism who had an adenoma of $18 \mathrm{~mm}$ diameter. The plasma aldosterone before procedure
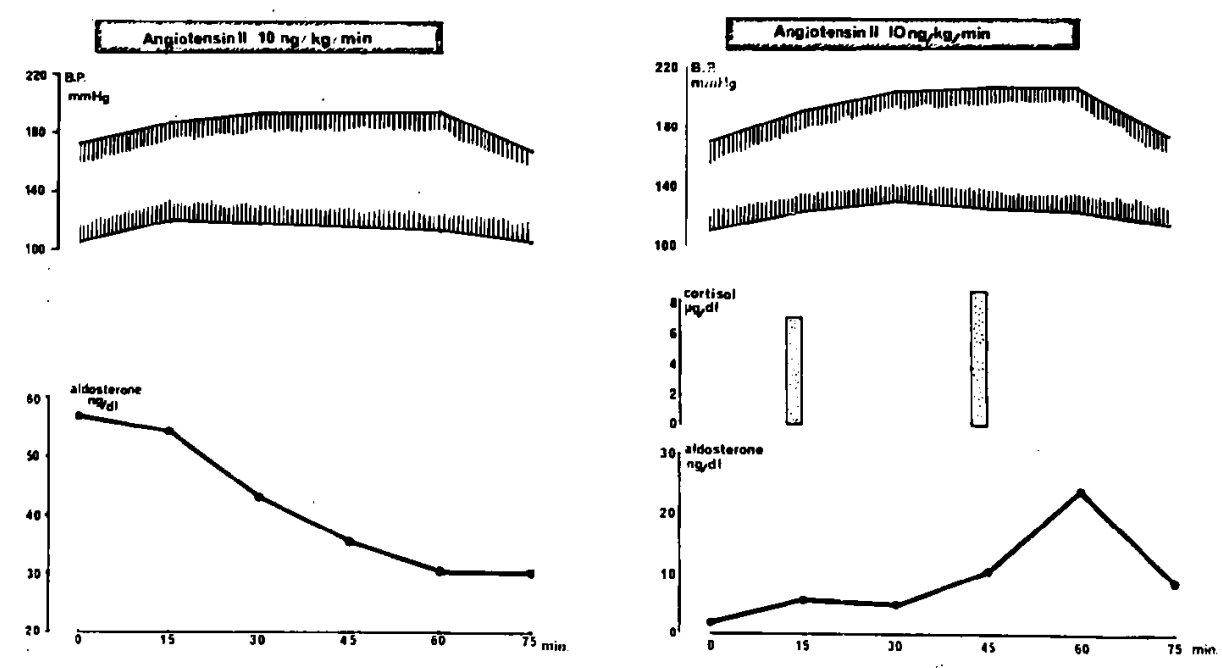

Fig. 5. The response of plasma aldosterone level to Angiotensin II $10 \mathrm{ng} / \mathrm{Kg} / \mathrm{min}$ infusion in primary aldosteronism (left: before operation; right: after operation). 


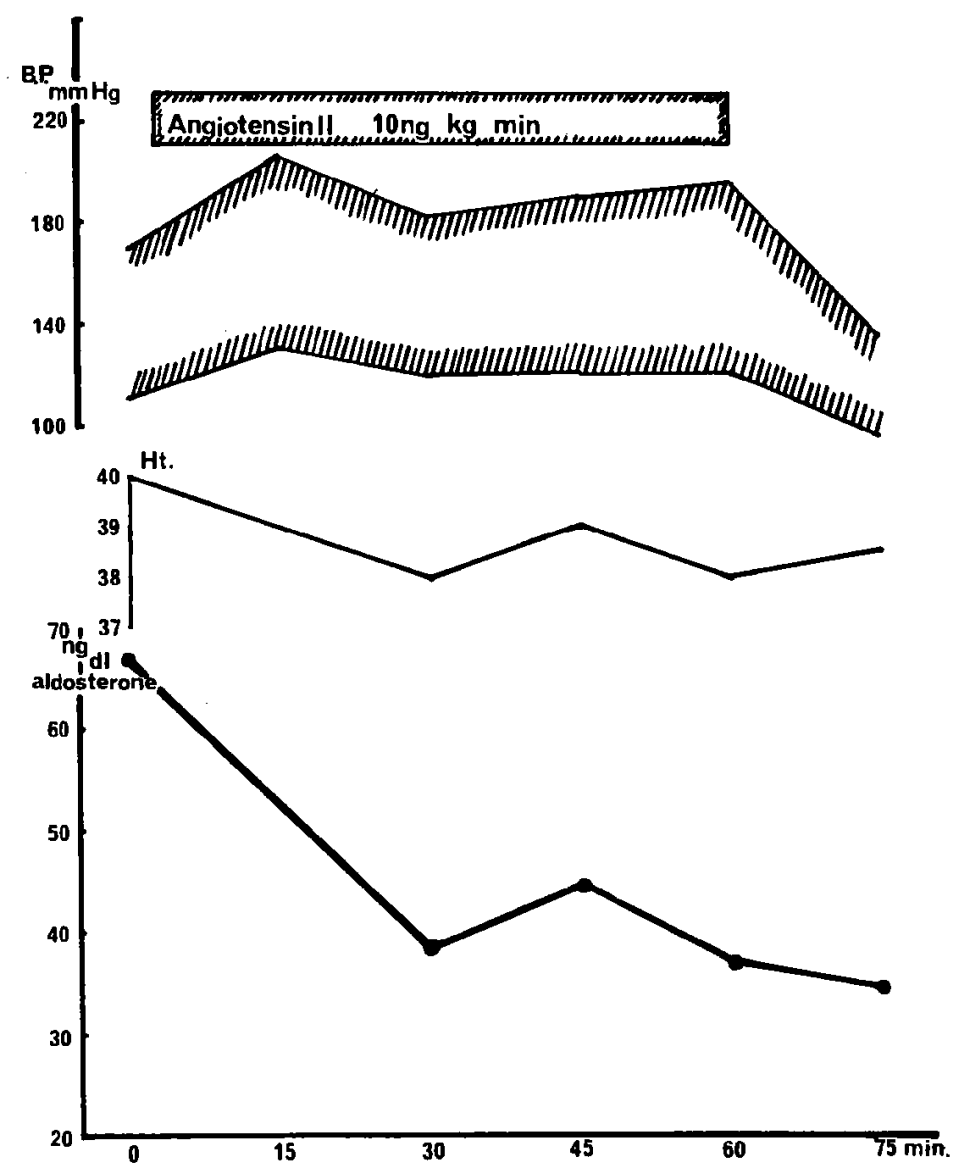

Fig. 6. The response of plasma aldosterone level to Angiotensin II $10 \mathrm{ng} / \mathrm{Kg} / \mathrm{min}$ infusion in primary aldosteronism who had adenoma.

was $66.7 \mathrm{ng} / 100 \mathrm{ml}$. At an interval of $15 \mathrm{~min}$ after that, the values were $38.5,44.8,36.9$, and $33.4 \mathrm{ng} / 100 \mathrm{ml}$. Hematocrit was decreased slightly from $40 \%$ to $38 \%$. Systolic and diastolic blood pressure were increased $37 \mathrm{mmHg}$ and $20 \mathrm{mmHg}$ respectively.

Fig. 7 (left) shows the result in nephrotic syndrome. Before procedure it was $32.2 \mathrm{ng} / 100 \mathrm{ml}$ and after that the values were $54.1,78.9,78.8,52.0$, and $56.0 \mathrm{ng} / 100 \mathrm{ml}$. Hematocrit was decreased markedly from $44.5 \%$ to $39 \%$. Systolic and diastolic blood pressure were increased $43 \mathrm{mmHg}$ and $38 \mathrm{mmHg}$ respectively.

Fig. 7 (right) shows the result of idiopathic edema. Before procedure it was $28.1 \mathrm{ng} / 100 \mathrm{ml}$, after the beginning of infusion 2 samples of 15 and $30 \mathrm{~min}$ showed as high as 74.5 and $70.3 \mathrm{ng} / 100 \mathrm{ml}$, but in spite of continuation of infusion, the values were gradually decreased to 27.3 and $21.7 \mathrm{ng} / 100 \mathrm{ml}$ and after the stop it became $13.7 \mathrm{ng} / 100 \mathrm{ml}$. 

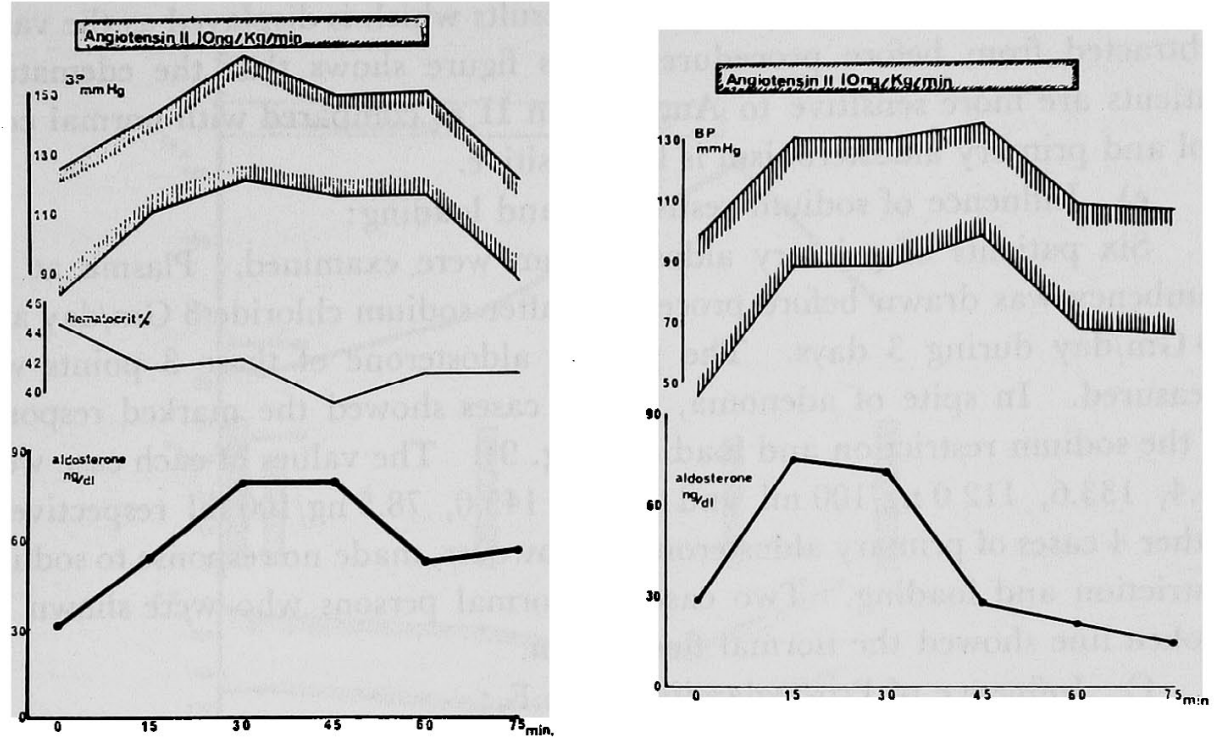

Fig. 7. The response of plasma aldosterone level to Angiotensin II $10 \mathrm{ng} / \mathrm{Kg} / \mathrm{min}$ infusion in nephrotic syndrome (left) and idiopathic edema (right).

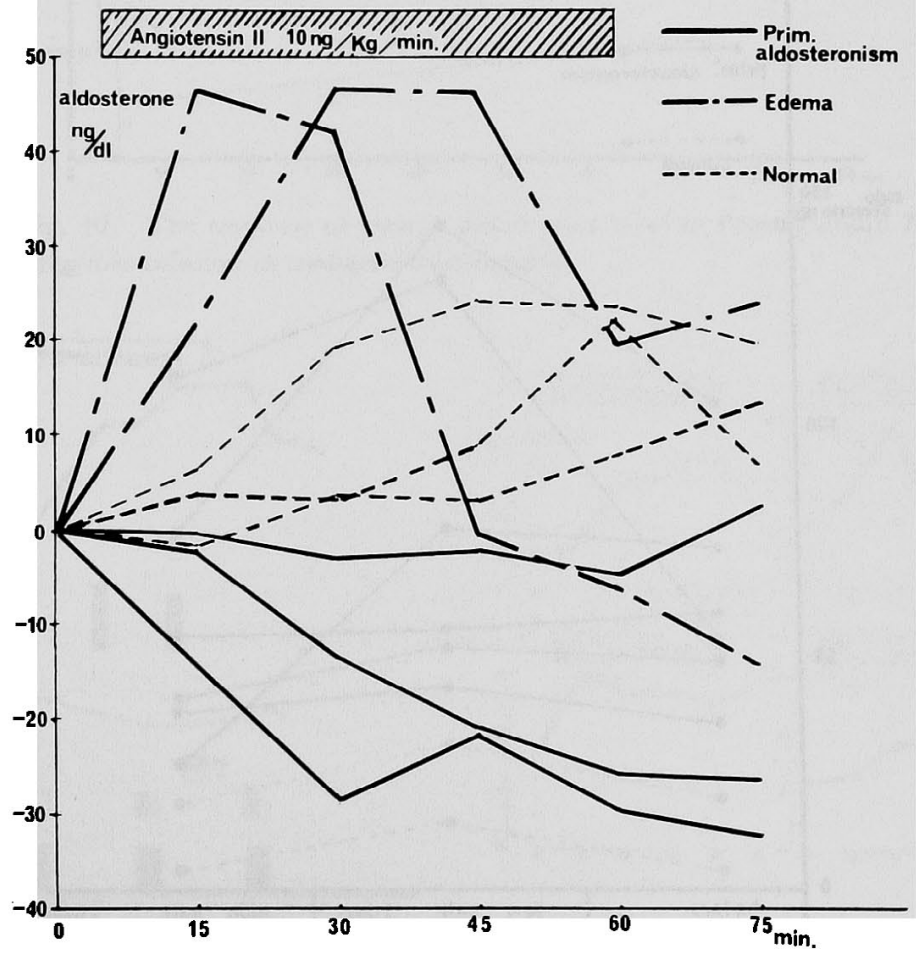

Fig. 8. The change of plasma aldosterone to Angiotensin II $10 \mathrm{ng} / \mathrm{Kg} /$ min infusion in normal volunteer, patients with edema and primary aldosteronism. Each plot was subtracted from the pre-infusion value. 
Fig. 8 shows the summary of these results which is displayed as the value subtracted from before procedure. This figure shows that the edematous patients are more sensitive to Angiotensin II as compared with normal control and primary aldosteronism is less sensitive.

e) Influence of sodium restriction and loading:

Six patients of primary aldosteronism were examined. Plasma at recumbency was drawn before procedure, after sodium chloride $3 \mathrm{Gm} /$ day and $20 \mathrm{Gm} /$ day during 3 days. The plasma aldosterone of these 3 points was measured. In spite of adenoma, 2 of 6 cases showed the marked response to the sodium restriction and loading (Fig. 9). The values of each case were $54.4,133.6,112.0 \mathrm{ng} / 100 \mathrm{ml}$ and $105.5,145.0,78.5 \mathrm{ng} / 100 \mathrm{ml}$ respectively. Other 4 cases of primary aldosteronism, however, made no response to sodium restriction and loading. Two cases of normal persons who were shown by broken line showed the normal fluctuation.

f) Influence of Prostaglandin $A_{2}$ or $E_{1}$ :

Fig. 10 shows the influence of Prostaglandin $A_{2}$ to the patient with malignant hypertension. Prostaglandin $A_{2} 50 \mathrm{ng}$ per $\mathrm{Kg}$ per minute was

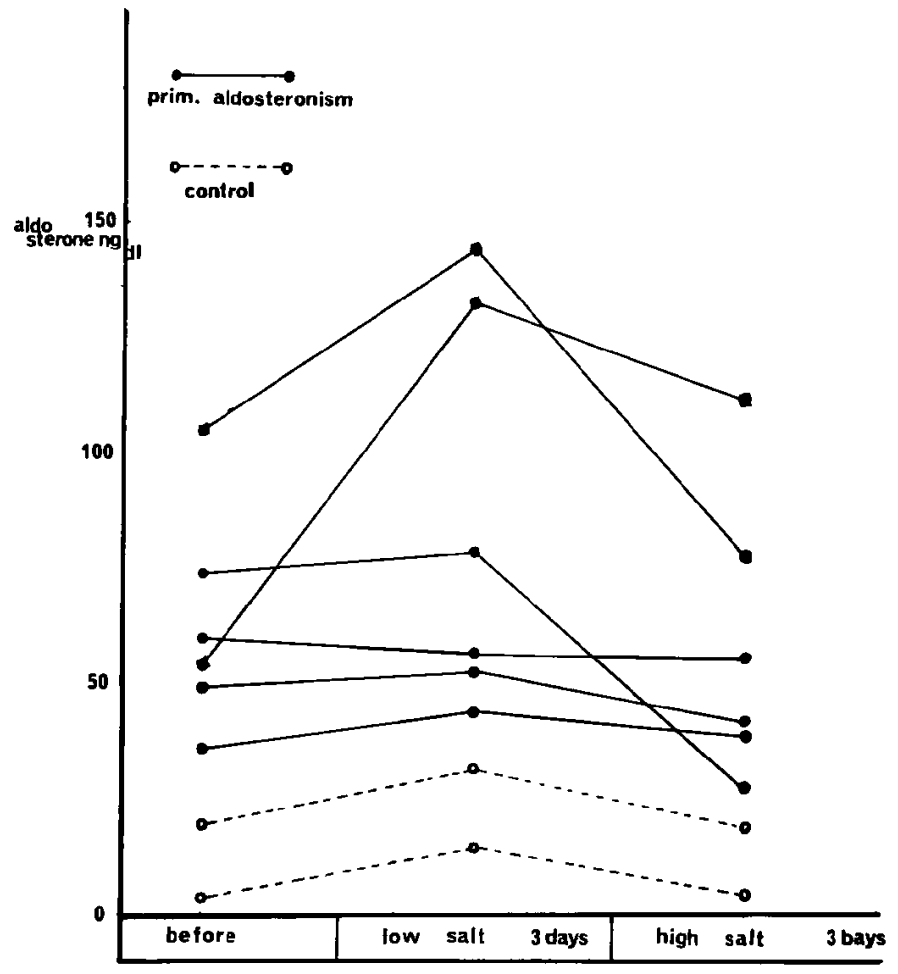

Fig. 9. The change of plasma aldosterone level by low salt diet (sodium chloride $3 \mathrm{Gm} /$ day) for 3 days and high salt diet (sodium chloride $20 \mathrm{Gm} /$ day) for 3 days. 


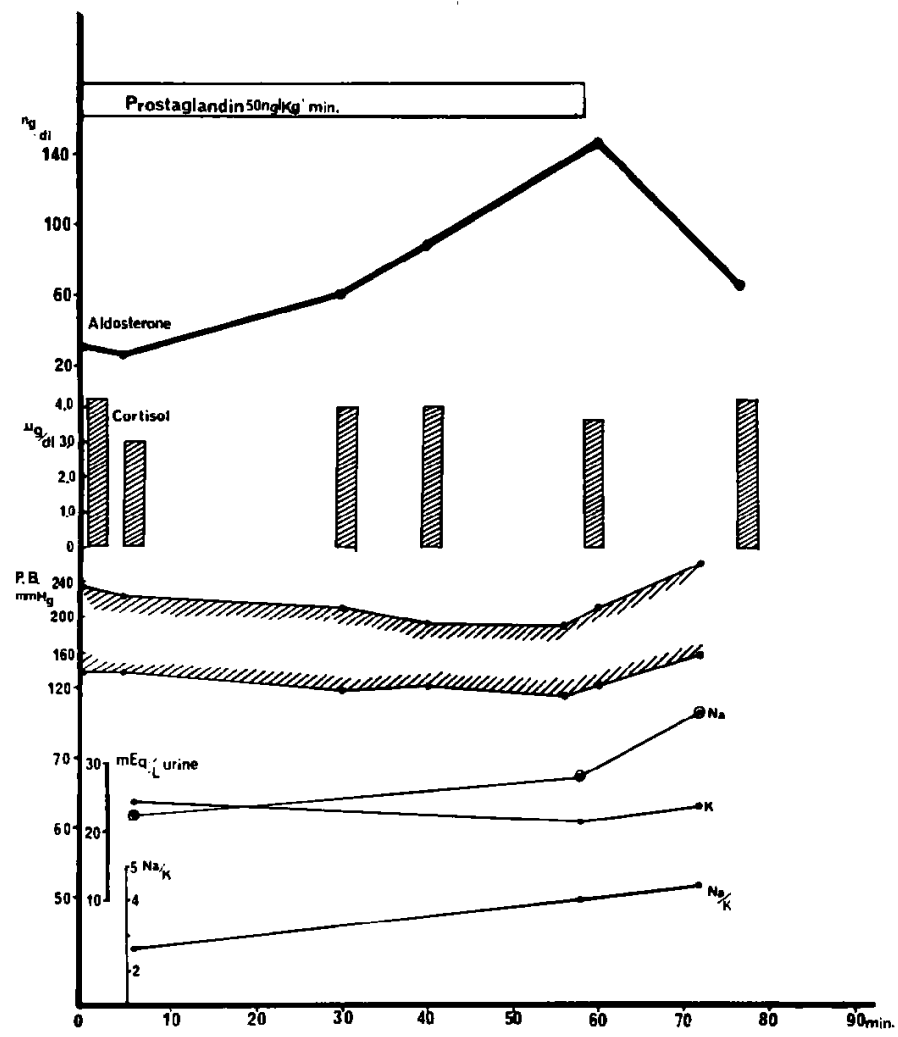

Fig. 10. The response of plasma aldosterone level to Prostaglandin $\mathbf{A}_{2}$ $50 \mathrm{ng} / \mathrm{Kg} / \mathrm{min}$ infusion in maligant hypertension.
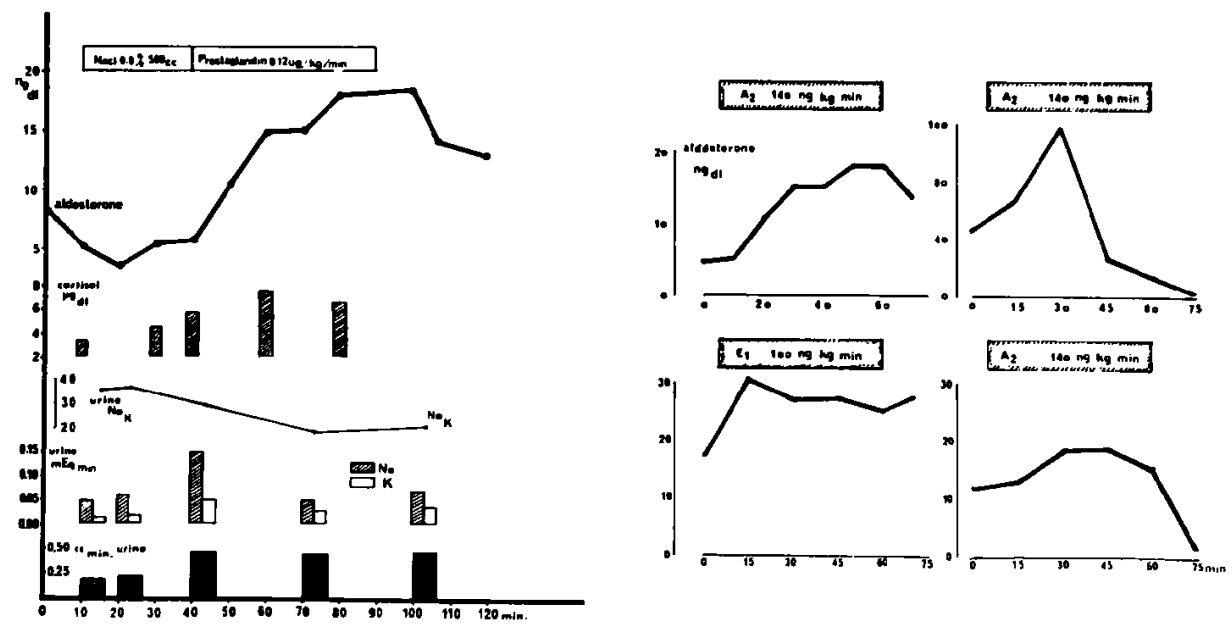

Fig. 11. The response of plasma aldosterone level in dog to Prostaglandin $A_{2} 120 \mathrm{ng} / \mathrm{Kg} / \mathrm{min}$ in saline solution (left). The same experiment obtained from Prostaglandin $A_{2} 140 \mathrm{ng}$ or $E_{1} 100 \mathrm{ng} / \mathrm{Kg} / \mathrm{min}$ infusion using 4 dogs (right). 
infused during 1 hour continuously. Blood pressure was gradually decreased and the excretion of urinary sodium was slightly increased. Despite no change of plasma cortisol, the plasma aldosterone was gradually increased. The values were $30.0,26.1,60.5,89.1,149.3$, and $67.8 \mathrm{ng} / 100 \mathrm{ml}$ respectively.

Fig. 11 (left) is an example which was tried to a dog. Before using of Prostaglandin $\mathrm{A}_{2} 120 \mathrm{ng}$ per $\mathrm{Kg}$ per minute, saline solution $500 \mathrm{ml}$ was infused. The values of each spot were $8.4,5.2,3.4,5.5,5.7,16.3,14.9,15.0,17.8,18.2$, 13.9 , and $12.6 \mathrm{ng} / 100 \mathrm{ml}$ respectively. The increased urinary volume and sodium excretion will be due to the sodium diuresis. The decreased plasma aldosterone will be also due to volume expansion. Prostaglandin $\mathrm{A}_{\mathbf{2}} 120 \mathrm{ng}$ per $\mathrm{Kg}$ per minute in saline solution $500 \mathrm{ml}$, however, increased the plasma aldosterone.

Fig. 11 (right) shows the various types of effect to plasma aldosterone, when Prostaglandin $A_{2}$ or $E_{1}$ was infused, but it seems that the effect was not so strong as in Angiotensin II infusion.

\section{Discussion}

Recently by the development of radioimmunoassay method, the measurement of plasma aldosterone became easy and rapid. Although the measurement of urine aldosterone excretion and secretion rate so far in use gave us many useful information, it was impossible to observe the plasma aldosterone level in short time interval.

This paper showed not only the plasma aldosterone in various diseases but also the sequential change of it in various stimulation. At recumbency in morning of normal volunteer without diet control, all values were less than $10 \mathrm{ng} / 100 \mathrm{ml}$, the values of plasma aldosterone in primary aldosteronism were scattered widely.

The maximum was $244 \mathrm{ng} / 100 \mathrm{ml}$ and minimum was $28 \mathrm{ng} / 100 \mathrm{ml}$ which was near the upper value of normal range. These results were almost same with the data of Fukuchi' ${ }^{1)}$ and Brown. ${ }^{2)}$ From these results it will be said that the upper limit of normal range can not always deny the primary aldosteronism.

In fact, the plasma aldosterone in a primary aldosteronism showed the day-to-day variations. Although chronic nephritis with uremia showed the upper limit of normal control, some cases of malignant hypertension showed high value. All of essential hypertension were normal value, but congestive heart failure with edema was relatively high value. Congenital adrenal hyperplasia, Bartter's syndrome and liver cirrhosis with edema showed markedly high value. 
Gowenlock (1959) ${ }^{3)}$ reported the urinary aldosterone excretion due to postural change. The plasma aldosterone due to postural change is found in the paper of Wolff and Torbica (1963).4) Michalakis and Horton reported the relation between plasma renin and aldosterone in postural change.

Sympathicotonia caused by upright stimulates the afferent arteriole of glomeruli which induces the increased renin secretion. This increased renin accelerates the aldosterone secretion through the Angiotensin II. Upright from recumbency decreases the hepatic blood flow, consequently the plasma aldosterone increases. In all cases of control the plasma aldosterone after 2 hours of upright and walking more or less increased.

Many papers describing about the relation between edema and aldosterone are found. Luetscher $(1954)^{5)}$ found that nephrotic patient excreted urine containing much aldosterone, thereafter this was watched as the substance causing edema.

It is now recognized, however, that 1) the congestive heart failure in stable equilibrium of hemodynamic condition does not always show the high urinary aldosterone excretion, 2) the patient of primary aldosteronism who is excreting much aldosterone in urine does not always show edema, 3 ) by the administration of a large amount of aldosterone during 1 or 2 weeks, so-called escaped phenomenon appears. This escaped phenomenon, however, does not appear in congestive heart failure. ${ }^{6)}$ Such a fact comes into problem when discussing about the role of aldosterone in edema.

In the above-mentioned results, the plasma aldosterone of normal control increased by diuresis. This fact will be explained by the feed-back mechanism due to sodium diuresis.

On the other hand, that of patients with edema was immediately decreased by diuresis. This fact may mean that the improvement of regulatory mechanism of water and electrolytes decreased the plasma aldosterone. Even in such patient, however, the plasma aldosterone was markedly increased after disappearing of diuretic effect as described before. Such a phenomenon cannot be explained only from the improvement of homeostasis. It looks like the body has set about to strive again for the restoration of lost sodium and water.

In normal control Angiotensin II stimulates the secretion of aldosterone as already known." Aldosterone secretion in nephrotic syndrome showed the higher sensitivity to Angiotensin II infusion than normal control.

In primary aldosteronism the plasma aldosterone was decreased by Angiotensin II infusion unexpectedly. Ganong $(1966)^{8)}$ said that the long time suppressed plasma renin activity decreased the reactivity of aldosterone stimulation to Angiotensin II, on the other hand, the increased plasma renin activity 
increased it.

Response of plasma aldosterone to low or high sodium intake was seen in 2 cases of primary aldosteronism with adenoma. This suggests the participation of auto-regulatory system in some cases of primary aldosteronism.

Recently Fichman and Horton (1972) ${ }^{9)}$ reported that Prostaglandin $A_{1}$ increased the plasma aldosterone significantly. His result agrees with this paper. In over a half of his cases the increased plasma aldosterone was unaccompanied by the increased plasma cortisol or plasma renin activity. From these results he concluded that Prostaglandin may either have a direct physiological role in the regulation of aldosterone secretion or may influence aldosterone indirectly consequent to Prostaglandin induced natriuresis.

\section{REFERENGES}

1. Fukuchi S, Takenouchi T, Nakajima K: Folia Endocrinologica Japonica 49: 747, 1973

2. Brown JJ, Chinn RH, Davis DL, Duterdich G, Fraser R, Lever AF, Robertson JIS, Free M, Wisema A: Lancet ii: 55, 1968

3. Gowenlock AH, Mills JN, Thomas S: J Physiol 146: 133, 1959

4. Wolff HP, Torbica M: Lancet i: 1346,1963

5. Luetscher JA, Johnson BB: J Clin Invest 33: 1441, 1954

6. Ito T, Nagasaka M, Yoshitoshi Y et al: Jap Heart J 8: 252, 1967

7. Michalakis AM, Horton R: Circulat Res 26 \& 27 (Suppl): I-185, 1970

8. Ganong WF, Biglieri EG, Mulrow PJ: Recent Progr Hormone Res 22: 381, 1966

9. Fichman MP, Littenburg G, Brooker G, Horton R: Circulat Res 31 (Suppl II): II-19, 1972 